\title{
Proctocolite induzida por proteína alimentar em lactente sob aleitamento materno exclusivo
}

\section{Food-protein induced proctocolitis in an exclusive breastfed infant}

Data de receção / Received in: 15/1 1/2017 Data de aceitação / Accepted for publication in: 23/04/2018

Rev Port Imunoalergologia $2019 ; 27$ (I):55-59

Carolina Prelhaz', Anna Sokolova², Carlos Escobar ${ }^{2}$, Marta Moniz², Pedro Nunes², Clara Abadesso², Helena Loureiro²

I Centro Hospitalar Barreiro Montijo, Setúbal

${ }^{2}$ Hospital Prof. Doutor Fernando Fonseca, Amadora

\section{RESUMO}

Introdução: A protocolite induzida por proteína alimentar é uma reação de hipersensibilidade não-lgE mediada, mais frequentemente desencadeada pela ingestão de leite de vaca ou soja mas também já reconhecida no contexto de aleitamento materno exclusivo. Pode manifestar-se nas primeiras semanas de vida e o seu diagnóstico constitui um desafio pela inespecificidade das manifestações clínicas, muitas vezes levando a intervenções médicas desnecessárias e invasivas. Caso clínico: Os autores apresentam um lactente com um mês de vida sob aleitamento materno exclusivo, avaliado por dejeções hemáticas, recusa alimentar e irritabilidade, cuja investigação clínica foi consecutivamente negativa e cujas manifestações clínicas reverteram após evicção do leite materno e início de leite extensamente hidrolizado. Conclusões: A evicção da proteína alimentar desencadeante resulta numa recuperação clínica geralmente completa e sem sequelas tardias. Pode ser necessária a suspensão do aleitamento materno em lactentes nos quais não seja identificada outra causa para a hipersensibilidade.

Palavras-chave: Proctocolite, hipersensibilidade, leite materno. 


\section{ABSTRACT}

Introduction: Food-protein induced proctocolitis is a non-IgE mediated hypersensitivity reaction, most often triggered by the ingestion of cow's or soy milk but it has also been recognized in exclusive breastfed infants. It may occur in the first weeks of life and its diagnosis is challenging given the lack of specificity of clinical manifestations, often leading to invasive and unnecessary medical interventions. Clinical report: The authors present a one-month old infant, exclusively breastfed, admitted for bloody stools, irritability and declining oral intake, whose clinical investigation was consecutively negative and whose clinical manifestations reversed after excluding breast milk eviction and introducing of extensively hydrolyzed milk. Conclusions: The exclusion of the triggering food protein usually leads to complete clinical response and no late sequelae. It may be necessary to stop breastfeeding in infants in whom no other cause for hypersensitivity has been identified.

Keywords: proctocolitis; hypersensitivity; breast milk

\section{INTRODUÇÃO}

A proctocolite induzida por proteína alimentar (PCIPA) é uma hipersensibilidade alimentar não $\lg$ E mediada, cujo mecanismo fisiopatológico não está ainda bem esclarecido 1,2,4,6. Leite de vaca e soja são os desencadeantes mais comuns, mas alimentos sólidos podem estar implicados ${ }^{1,2,3,5,6}$.

A PCIPA pode manifestar-se nas primeiras semanas de vida, de forma aguda ou crónica, sendo a última mais rara, associada a início mais precoce e a sintomas menos exuberantes (vómitos intermitentes, diarreia hemática, má progressão ponderal e letargia) $)^{1,4,8}$ e estando já descrita em recém-nascidos (RN)/lactentes sob aleitamento materno exclusivo $0^{6,7,8}$.

O diagnóstico é essencialmente clínico e muitas vezes tardio, por não haver um teste diagnóstico definitivo ou manifestações cutâneas e respiratórias concomitantes $^{3}$, com remissão dos sintomas após evicção do agente desencadeante ${ }^{2,3}$. Implica diagnóstico diferencial com outras situações clínicas de natureza alérgica, infecciosa, cirúrgica, metabólica, hematológica ou imunológica ${ }^{4,9}$, levando frequentemente a tratamentos desnecessários ${ }^{4}$.
A maioria adquire tolerância alimentar no primeiro ano de vida, devendo esta ser documentada por prova de tolerância oral ${ }^{2,3}$.

\section{CASO CLÍNICO}

Lactente do sexo masculino, sob aleitamento materno exclusivo desde o nascimento, com adequada progressão ponderal. História de períodos prolongados de choro inconsolável desde o nascimento. Pais com história de asma moderada.

Com um mês de vida submetido a herniorrafia inguinal bilateral. Alta no próprio dia, clinicamente bem e a tolerar leite materno. No mesmo dia, por dejeções com muco e vestígios de sangue, recusa alimentar e irritabilidade, recorreu ao serviço de urgência pediátrico.

À admissão objetivava febre $\left(38,6^{\circ} \mathrm{C}\right)$, gemido e má perfusão periférica, com distensão abdominal. Analiticamente destacava-se: $\mathrm{Hb} 8,6 \mathrm{~g} / \mathrm{dL}$, leucócitos $7500 / \mathrm{mm}^{3}$, plaquetas $384000 / \mathrm{mm}^{3}$, PCR I,76mg/dL. Gasimetria venosa sem alterações.

Pela distensão abdominal, realizou ecografia que revelou espessamento parietal do íleo terminal, cego e 
colon ascendente, com episódios de peristaltismo aumentado e marcada distensão gasosa. Mostrou também lâmina de líquido interansas em topologia pélvica e formações ganglionares infracentimétricas. Estas alterações foram descritas como sugestivas de invaginação intestinal intermitente, sem indicação cirúrgica urgente, tendo sido admitido para vigilância na Unidade de Cuidados Intensivos Pediátricos, em pausa alimentar.

Manteve-se em ar ambiente e com frequências cardíacas (FC) entre 150 e 170 bpm. Por manter febre repetiu avaliação analítica em DI de internamento: $\mathrm{Hb}$ 7,I $\mathrm{g} / \mathrm{dL}$ e PCR 5,6 mg/dl. Foi decidida transfusão de concentrado eritocitário em D2 por aumento da FC. Pela subida dos parâmetros de infeção realizou punção lombar, com exame citoquímico negativo. Apesar de se encontrar sem febre em D2 de internamento, iniciou ampicilina, cefotaxima e metronidazol, que suspendeu em D4 após exames culturais (urocultura, líquor e hemocultura) negativos. Repetiu ecografia abdominal, que revelou espessamento parietal do cólon, com pequena quantidade de líquido puro interansas nos quadrantes direitos.

Perante o quadro de dejeções hemáticas, realizou cintigrafia que excluiu divertículo de Meckel. Pesquisa de rotavírus, E. coli O:157, Campylobacter, Yersinia, Salmonella e Shigella nas fezes negativa. Toxina de Clostridium dificille negativa.

Ainda em DI de internamento iniciou alimentação entérica com leite extensamente hidrolizado, com tolerância e regressão das dejeções hemáticas. Reiniciou aleitamento materno em D2. Em D3, por aparecimento de exantema maculopapular de distribuição centrífuga, poupando os membros inferiores, e edema palpebral bilateral, com nova dejeção com sangue vivo, retomou leite extensamente hidrolizado, com resolução das alterações descritas. Neste contexto, foi avaliado por Imunoalergologia, tendo sido pedidas IgE específicas para leite total, alfa-lactoalbumina, beta-lactoglobulina e caseína, todas com resultado <0,35 $\mathrm{kU} / \mathrm{l}$. Não foram realizados, no internamento, testes cutâneos por picada.
Foi considerada como hipótese diagnóstica provável proctocolite induzida por proteínas alimentares, com resposta cutânea após reintrodução do leite materno. Teve alta em D7 de internamento, clinicamente bem, mantendo alimentação com leite extensamente hidrolizado para o domicílio, por decisão dos pais.

\section{DISCUSSÃO}

A hipersensibilidade alimentar consiste numa resposta imunológica anormal a proteínas alimentares, podendo apresentar-se clinicamente de formas diversas: reações mediadas por lgE, reações mistas (mediadas por lgE e por células) e reações mediadas por células. Nestas últimas incluem-se a enteropatia (EPIPA), proctocolite (PCIPA) e enterocolite (EIPA), induzidas por proteínas alimentares, a doença celíaca e a hemossiderose pulmonar, induzida por alimentos ${ }^{2,3}$.

As reações de hipersensibilidade mediadas por células parecem ser mais frequentes no sexo masculino e associar-se a antecedentes pessoais ou familiares de atopia ${ }^{2,3}$. Os sintomas surgem tipicamente entre $\circ 1 .^{\circ}$ e $\circ 3 .^{\circ}$ meses de vida, embora os relacionados com alimentos sólidos tendam a surgir mais tardiamente, com a diversificação alimentar ${ }^{2}$. O leite de vaca e soja são os alimentos mais frequentemente implicados ${ }^{1,2,3,5,6}$. Também reações de hipersensibilidade não-lgE mediadas desencadeadas por proteínas presentes no leite materno são possíveis e devem ser consideradas na presença de cenário clínico sugestivo $^{8}$. Embora raras, reações alérgicas, como urticária e anafilaxia associadas à ingestão de leite materno, têm sido descritas ${ }^{7}$.

As manifestações clínicas e laboratoriais de EIPA e PCIPA são diferentes: EIPA pode manifestar-se durante o primeiro ou segundo anos de vida, enquanto PCIPA se manifesta mais frequentemente nos primeiros 6 meses e geralmente nas primeiras 4 semanas de vida, ocasionalmente em lactentes sob aleitamento materno exclusivo ${ }^{2,3}$. Nestes, as alterações clínicas são geralmente mais insi- 
diosas ${ }^{3}$. Contrariamente ao observado na EIPA, em que a emese é mais exuberante, podendo haver progressão para choque hipovolémico e acidemia, na PCIPA a característica mais significativa é a presença de dejeções pastosas com sangue em lactente com bom estado geral, ocasionalmente com cólica mas raramente com progressão para desidratação ${ }^{2,3}$. Nestes, anemia e hipoalbuminemia são $\operatorname{raras}^{2,3}$. No caso apresentado, a anemia deveu-se, provavelmente, não só a perdas intestinais ocultas no contexto da proctocolite, mas também a perdas relacionadas com o procedimento cirúrgico realizado. Considerando as características clínicas e laboratoriais de ambas as situações clínicas, o caso clínico apresentado parece ser mais sugestivo de PCIPA. As alterações descritas colocam diagnóstico diferencial com fissura anal, gastroenterite infeciosa, anafilaxia, alterações metabólicas, sépsis, invaginação intestinal ou enterocolite necrotizante, muitas vezes culminando em tratamento antibiótico e intervenções invasivas desnecessárias ${ }^{3,4,9}$. Endoscopicamente, a colite é mais exuberante na EIPA e mais focal na PCIPA ${ }^{3}$. A PCIPA parece resolver mais precocemente, geralmente nos primeiros 12 meses de vida ${ }^{2,3}$.

As provas de provocação oral são o gold standard diagnóstico. No entanto, não são necessárias na maioria dos lactentes, especialmente quando existe história clínica sugestiva, com resolução dos sintomas após evicção do alimento desencadeante ${ }^{1,2,3}$. A prova de provocação oral é importante na documentação da tolerância, devendo ser realizada depois dos 12 meses de idade nas hipersensibilidades induzidas pelas proteínas do leite de vaca ou, mais precocemente, a partir dos 6 meses, se hipersensibilidade à soja ${ }^{2}$. A maioria dos doentes tem testes cutâneos por picada (TCP) negativos e IgE específicas indetetáveis na altura do diagnóstico. Só muito raramente os doseamentos de lgE específicas são positi$\operatorname{vos}^{1,2,6}$ e estes casos parecem associar-se a doença mais grave e/ou prolongada e até apresentar alteração do fenótipo clínico para o de reação de hipersensibilidade imediata $^{2,3}$. Apesar de os TCP se mostrarem promissores no diagnóstico desta condição, ainda não estão estabe- lecidos como testes diagnósticos ou de aquisição de tolerância, parecendo no entanto existir uma relação entre a positividade dos TCP e a ausência de aquisição de tolerância oral².

Em RN/lactentes sob aleitamento materno exclusivo a eliminação do agente desencadeante da dieta materna resulta geralmente numa resolução gradual dos sintomas ${ }^{3}$. No caso clínico apresentado, no entanto, a evicção do agente desencadeante da dieta materna não foi tentada, por decisão dos pais. Mais raramente, a persistência de hemorragia intestinal, apesar de evicção materna adequada, pode dever-se a incorreta identificação da proteína desencadeante ou a hipersensibilidade às próprias proteínas do leite materno ${ }^{3}$.

A hipersensibilidade gastrointestinal mediada por células a proteínas alimentares parece ser uma condição autolimitada e sem sequelas, exceto naqueles com lgE específicas positivas ${ }^{3}$. Alguns estudos descrevem progressão para doença atópica (eczema, asma). Parece haver um maior risco de alergia alimentar lgE mediada no grupo de doentes com EIPA. Não existem documentados casos de progressão para doença inflamatória intestinal ${ }^{3}$.

Um baixo índice de suspeição é a principal causa de atraso diagnóstico ${ }^{4}$. Com este caso os autores pretendem alertar para esta condição clínica que tem vindo a ser reconhecida de forma crescente, mesmo em RN/lactentes sob aleitamento materno exclusivo.

\section{Contacto:}

Carolina Prelhaz

Centro Hospitalar Barreiro Montijo

Av. Movimento das Forças Armadas, 2830-003 Barreiro

E-mail: carolinaprelhaz@gmail.com

\section{REFERÊNCIAS}

I. Ludman S, Harmon M, Whiting D, du Toit G. Clinical presentation and referral characteristics of food protein-induced enterocolitis syndrome in the United Kingdom. Ann Allergy Asthma Immunol 2014;।I3:290-4. 
2. Cruz C, Didenko I, Ferreira F, Inácio F. Enterocolite induzida por proteínas alimentares. Rev Port Imunoalergologia. 2014;22:II-2I.

3. Nowak-Węgrzyn A. Food protein-induced enterocolitis syndrome and allergic proctocolitis. Allergy Asthma Proc 2015;36:172-84.

4. Fiocchi A, Claps A, Dahdah L, Brindisi G, Dionisi-Vici C, Martelli A. Differential diagnosis of food protein-induced enterocolitis syndrome. Curr Opin Allergy Clin Immunol 2014;14:246-54.

5. Mehr S, Frith K, Campbell D. Epidemiology of food protein-induced enterocolitis syndrome. Curr Opin Allergy Clin Immunol 2014;14:208-16.

6. Yang M, Geng L, Xu Z, Chen P, Friesen C, Gong S, et al. Severe food protein-induced enterocolitis syndrome to cow's milk in infants. Nutrients 2016;8:1.
7. Miceli S, Monaco S, Greco M, Scala G. Chronic food protein-induced enterocolitis syndrome caused by cow's milk proteins passed through breast milk. Int Arch Allergy Immunol 2014;164:207-9.

8. Monti G, Castagno E, Liguori S, Lupica M, Tarasco V, Viola S, et al. Food protein-induced enterocolitis syndrome by cow's milk proteins passed through breast milk. J Allergy Clin Immunol 2011;127:679-80.

9. Jayasooriya S, Fox A, Murch S. Do not laparotomize food protein-induced enterocolitis syndrome. Pediatr Emerg Care 2007; 23:173-5.

10. Mehr S, Kakakios A, Frith K, Kemp AS. Food protein-induced enterocolitis syndrome: 16-year experience. Pediatrics 2009; 123:e459-64. 